\title{
Температуры кристаллизации лейкосом Беломорской эклогитовой провинции
}

Картушинская Т.В., Горбунов И.А.

Геологический институт КНЦ РАН, Anamumb, tanja_1992@mail.ru

Аннотация. История геологического развития докембрийской Беломорской эклогитовой провинции включает в себя несколько этапов деформации и метаморфизма, включая мигматизацию. Для лейкосом мигматитов была рассчитана температура кристаллизации с использованием модели растворимости циркона в анатектических расплавах. Цирконы из лейкосом в мигматизированных ТТГ гнейсах и амфиболитах с реликтами эклогитов на участках Куру-Ваара и Гридино были датированы U-Pb методом на вторично-ионном масс-спектрометре SHRIMP II. Циркон имеет сложное зональное строение, которое обусловлено неоднократностью проявленных событий. Рассчитанные температуры коррелируются с самыми поздними генерациями цирконов в каждой из лейкосом, то есть с наиболее поздними событиями. Для участка Куру-Ваара температура кристаллизации тоналитовой лейкосомы возраста 2.83 млрд. лет в диафторированных эклогитах составляет 760-770 ${ }^{\circ} \mathrm{C}$, для лейкосомы возраста 1.93 млрд. лет в ТТГ гнейсах $-610-620^{\circ} \mathrm{C}$; для лейкосом возраста 1.88-1.89 млрд. лет в амфиболитах и диафторированных эклогитах $-610-640^{\circ} \mathrm{C}$. Для лейкосомы участка Гридино с возрастом 1.94 млрд лет полученная температура кристаллизации составляет $760-770^{\circ} \mathrm{C}$.

Ключевые слова: мигматизация; лейкосома; Беломорье; Фенноскандинавский щит; ТТГ гнейсы.

\section{Leucosomes crystallization temperatures in the Belomorian eclogite province}

\author{
Kartushinskaya T.V., Gorbunov I.A. \\ Geological institute KSCRAS, Apatity,tanja_1992@mail.ru
}

\begin{abstract}
Geological evolution of the Precambrian Belomorian eclogite province comprises several stages of deformational and metamorphic events, including migmatization. Leucosomes crystallization temperatures were calculated using a model of zircon solubility in anactectic melts. Zircons in leucosomes in migmatized TTG gneisses and amphibolites wth relics of eclogites in the Kuru-Vaara and Gridino study areas were analyzed by the U-Pb SIMS (SHRIMP II) technique. The zircons exhibit a complex zoning due to their multi-staged geological history. Calculated temperatures are correlated with youngest generations of the zircons for each leucosome, i.e. with latest deformational and metamorphic events. Following crystallization temperatures were calculated in the Kuru-Vaara area: (1) 610$620^{\circ} \mathrm{C}$ for tonalitic leucosome with an age of $2.83 \mathrm{Ga}$ in retrogressed eclogites; (2) $610-620^{\circ} \mathrm{C}$ for leucosome with age $1.93 \mathrm{Ga}$ in TTG gneisses; (3) $610-640^{\circ} \mathrm{C}$ for leucosome with age 1.88-1.89 Ga in amphibolites and retrogressed eclogites. Crystallization temperatures of leucosome from the Gridino area with an age of $1.94 \mathrm{Ga}$ is calculated as $760-770^{\circ} \mathrm{C}$.
\end{abstract}

Key words: migmatization; leucosome; Belomorian province; Fennoscandian Shield; TTG gneisses.

\section{Введение}

Возраст беломорских ультравысокобарических эклогитов определяет время начала действия тектоники литосферных плит в близком к современному виде. Один из подходов к оценке возраста эклогитового метаморфизма заключается в изучении структурно-метаморфической эволюции эклогитсодержащих пород Беломорья и важную роль здесь играет гранитоидный магматизм, включая мигматитообразование, сопутствующий определенным этапам деформаций. Точный возраст того или иного деформационного события может быть определен путем изотопного датирования образовавшегося синхронно с ним гранитоидного материала.

В эклогитсодержащем амфиболито-гнейсовом комплексе Беломорского пояса было установлено несколько этапов деформаций и связанных с ними гранитных лейкосом (табл. 1). В данной работе приводятся данные о температурах кристаллизации этих структурно-привязанных лейко- 
сом. Для расчета температур кристаллизации использована методика, описанная в работе (Watson, Harrison, 1983).

\section{Геологическая обстановка}

Архейская Беломорская провинция сложена главным образом архейскими тоналиттрондьемит-гранодиоритовыми (далее серыми) гнейсами с разнообразными амфиболитами. Провинция представляет собой полиметаморфическую область, которая испытала неоднократные и интенсивные деформации (Володичев, 1990; Ранний докембрий..., 2005; Слабунов и др., 2006 а, 2006 б). Отличительной особенностью Беломорской провинции является широкое развитие раннедокембрийских эклогитов (Володичев и др., 2004; Mints et al., 2010; Щипанский и др., 2012 a). Эклогиты обнаруживаются в виде реликтов в телах архейских амфиболитов (Щипанский и др., $2012 \mathrm{a}$, 2012 б; Balagansky et al., 2015). Кроме того, известны эклогитовые парагенезисы в палеопротерозойских дайках базитов (Травин, Козлова, 2005; Мельник и др., 2013). Изотопное датирование эклогитов позволило выделить две принципиально разновозрастные группы эклогитов: (1) архейские с возрастом 2.87-2.72 млрд. (Володичев и др., 2004; Минц и др., 2010; Щипанский и др., 2012 a, 2012 б) и (2) палеопротеройские возрастом с 1.9 млрд. лет (Скублов и др., 2010 a, 2010 б; Мельник и др., 2013). Интерпретация этих датировок остается предметов дискуссий.

\section{Характеристика лейкосом}

Одними из наиболее изученных участков развития эклогитов являются район села Гридино, карьер Куру-Ваара, а также участок Салма (последний в данной работе не рассматривается).

Участок Kypy-Baара расположен в северной части Беломорской провинции. Он сложен преимущественно архейскими ТТГ гнейсами с прослоями и линзами амфиболитов с реликтами эклогитов. Развитие амфиболитов по эклогитам привело к преобразованию последних в симплектитовые эклогиты, которые затем были разлинзованы и мигматизированы. Мигматизация в пределах участках была проявлена неоднократно, в результате чего на участке установлено несколько генераций лейкосом, образовавшихся как в мезоархейское, так и в палеопротерозойское время.

Датирование лейкосом производилось по циркону U-Pb методом на вторично-ионном массспектрометре SHRIMP II (Картушинская, 2018). Циркон в большинстве проб имеет сложное зональное строение, которое обусловлено неоднократностью проявленных на участке событий. Т.к. расчет температуры кристаллизации производился по данным валовых химических анализов породы, то полученная температура должна отражать условия кристаллизации во время формирования самой молодой генерации циркона. В связи с этим в данной работе приводятся данные возраста самых поздних генераций циркона, определенных по их каймам.

Самой древней структурно-привязанной лейкосомой из установленных на участке КуруВаара является тоналитовая лейкосома (обр. КТ-17215; табл. 1, 2), которая расположена внутри крупного тела амфиболитов. Она окаймляет линзу с реликтами симплектитовых эклогитов, которые связаны с амфиболитом постепенными переходами, и резко отличается от всех лейкосом данного участка массивной мелкозернистой текстурой и серым цветом. Предполагается, что именно эта мигматизация и приводила к преобразованию ранних эклогитов в амфиболиты. Для этой лейкосомы установлен возраст $2829 \pm 11$ млн. лет. Её геологическое положение указывает на то, что возраст реликтов эклогитов древнее 2.83 млрд. лет.

В палеопротерозое установлена лейкосома (обр. Г-71325; табл. 1, 2) с возрастом $1933 \pm 59$ млн. лет,образовавшаяся до эклогитового метаморфизма 1.9 млрд. лет. Она сформировалась во время складчатых деформаций в ТТГ гнейсах, и расположена параллельно осевым поверхностям полулежачих открытых складок. Лейкосома имеет среднезернистую текстуру и сложена двуполевошпатовым гранитом. Дополнительно была продатирована проба вмещающего ТТГ гнейса (обр. Г-71325-10; табл. 1, 2). Проба была отобрана из однородной и массивной мезосомы мигматизированного ТТГ гнейса. Возраст самой поздней генерации циркона в этой пробе составляет $1961 \pm 46$, что в пределах аналитической погрешности совпадает с возрастом лейкосомы, и отражает одно и то же событие. 
Лейкосомы, образовавшиеся во время мигматизации и деформации тел амфиболитов с реликтами эклогитов, имеют возраст 1.88 млрд. лет. Эти события последовали сразу за эклогитовым метаморфизмом. Лейкогранитная лейкосома (обр. КТ-17216; табл. 1,2) была взята для датирования из того же обнажения, что и ранняя тоналитовая лейкосома (обр. КТ-17215). Лейкогранитная лейкосома имеет секущее положение по отношению к тоналитовой лейкосоме и находится на большем отдалении от центра линзы с реликтами эклогитов. Она также отличается от тоналитовой лейкосомы крупнозернистой текстурой и более кислым составом. Пегматоидная лейкосома (обр. КТ-813120; табл. 1,2$)$ развита субпараллельно осевым поверхностям складок вертикального раздавливания в мигматизированных амфиболитах. Лейкосома отделена от мезосомы ярко выраженной меланосомой и сложена кварцевым диоритом.

Участок Избная Луда представляет собой остров в районе с. Гридино. Этот район сложен серыми гнейсами архея, которые вмещают архейские амфиболиты с реликтами эклогитов (Володичев и др., 2004) и эклогитизированные палеопротерозойские дайки (Травин, Козлова, 2005). В строении острова выделены Западный, Центральный и Восточный домены, при этом серые гнейсы и дайки Восточного домена испытали в палеопротерозое интенсивное рассланцевание (Травин и др., 2005). В данном домене установлена сдвиговая зона, в которой отмечаются складки сдвигового течения. В замке одной из таких складок, параллельно её осевой поверхности, развита гранитная лейкосома возраста $1941 \pm 17$ млн. лет (обр. 81660; табл. 1, 2). Возраст этой лейкосомы отражает этап деформации и мигматизации, предшествовавший эклогитовому метаморфизму 1.9 млрд. лет.

Таблица 1. Содержание петрогенных элементов (масс. \%) и циркония (г/т) в структурно-привязанных лейкосомах.

Table 1. Major elements (wt. \%) and zirconium (ppm) analyses of structurally-constrained leucosomes .

\begin{tabular}{|cc|c|cc|c|l|}
\hline Образец & Г-71325-10 & $\Gamma-71325$ & KТ-813120 & КТ-17216 & КТ-17215 & 81660 \\
$\mathrm{SiO}_{2}$ & 66.29 & 71.34 & 67.38 & 74.79 & 68.51 & 70.38 \\
$\mathrm{TiO}_{2}$ & 0.43 & 0.12 & 0.21 & 0.10 & 0.56 & 0.29 \\
$\mathrm{Al}_{2} \mathrm{O}_{3}$ & 15.69 & 15.19 & 15.67 & 12.98 & 14.81 & 15.14 \\
$\mathrm{Fe}_{2} \mathrm{O}_{3}$ & 1.94 & 0.0 & 0.5 & 0.00 & 0.00 & 0.38 \\
$\mathrm{FeO}$ & 2.1 & 2.58 & 3.33 & 1.95 & 3.70 & \\
$\mathrm{MnO}$ & 0.071 & 0.02 & 0.035 & 0.007 & 0.041 & 0.040 \\
$\mathrm{MgO}$ & 1.76 & 0.37 & 1.28 & 0.14 & 1.43 & 0.55 \\
$\mathrm{CaO}$ & 4.29 & 3.02 & 3.93 & 2.51 & 3.24 & 4.02 \\
$\mathrm{Na}{ }_{2} \mathrm{O}$ & 4.26 & 4.45 & 4.78 & 2.81 & 4.78 & 5.28 \\
$\mathrm{~K}_{2} \mathrm{O}$ & 1.84 & 2.0 & 1.65 & 4.04 & 1.60 & 0.52 \\
$\mathrm{P}_{2} \mathrm{O}_{5}$ & 0.18 & 0.02 & 0.03 & 0.02 & 0.14 & 0.06 \\
$\mathrm{Zr}$ & 20.8 & 15.5 & 25.7 & 53.7 & 152 & 160 \\
\hline
\end{tabular}

Примечание. Анализы содержания петрогенных элементов выполнены в химико-аналитической лаборатории ГИ КНЦ РАН атомно-абсорбционным $\left(\mathrm{SiO}_{2}, \mathrm{Al}_{2} \mathrm{O}_{3}, \mathrm{Fe}_{2} \mathrm{O}_{3}, \mathrm{MgO}, \mathrm{CaO}, \mathrm{MnO}\right)$, эмиссионным $\left(\mathrm{K}_{2} \mathrm{O}, \mathrm{Na}_{2} \mathrm{O}\right)$, колориметрическим $\left(\mathrm{TiO}_{2}, \mathrm{P}_{2} \mathrm{O}_{5}\right)$, объемным $\left(\mathrm{CO}_{2}, \mathrm{FeO}\right)$ и весовым $\left(\mathrm{H}_{2} \mathrm{o}\right.$, п.п.п.) методами по одной навеске породы после разложения путем ее сплавления с бурой и содой. Аналитическая погрешность для $\mathrm{Fe}_{2} \mathrm{O}_{3}$ при содержании в породе $0.10-1.00$ мас. \% составляла $17 \%$, при содержании $1.00-10.0$ мас. \% - 7 \%; аналитическая погрешность для $\mathrm{FeO}$ равнялась $~ 6.5 \%$, у всех остальных элементов: для концентрации $1-10 \%-3.5 \%$; для концентрации $>10 \%-1.5 \%$. Анализы содержания циркония выполнены методом масс-спектрометрии с индуктивно связанной плазмой на приборе ELAN 9000 DRC-е в ИХTРЭМС КНЦ РAH.

\section{Результаты}

Для расчета температуры кристаллизации гранитоидов, сопутствующих определенным этапам деформаций на участках развития эклогитовых ассоциаций Беломорского пояса, была использована формула, приведенная в работе (Watson, Harrison, 1983):

$$
\ln \mathrm{D}_{\mathrm{Zr}}^{\text {zircon/melt }}=\{-3.80-[0.85(\mathrm{M}-1)]\}+12900 / \mathrm{T},
$$


где Т - температура насыщения для циркона (в $\left.{ }^{\circ} \mathrm{K}\right), \mathrm{D}_{\mathrm{Zr}}^{\text {zircon} / m e l t}-$ коэффициент распределения циркония между цирконом и расплавом, определяемый через отношение концентрации циркония в стехиометрическом цирконе ( $500000 \mathrm{ppm})$ и породе, $\mathrm{M}$ - катионные отношения [(Na $+\mathrm{K}+2 \mathrm{Ca}) /$ $(\mathrm{Al} \times \mathrm{Si})]$, рассчитанные по валовым содержаниям $\mathrm{SiO}_{2}, \mathrm{Al}_{2} \mathrm{O}_{3}, \mathrm{NaO}, \mathrm{K}_{2} \mathrm{O}$ и $\mathrm{CaO}$.

Полученные данные позволяют оценить температуру деформаций, наложенных на мезоархейские и палеопротерозойские эклогиты. Для участка Куру-Ваара температура кристаллизации тоналитовой лейкосомы возраста 2.83 млрд. лет в диафторированных эклогитах составляет 760-770 ${ }^{\circ} \mathrm{C}$, для лейкосомы возраста 1.93 млрд. лет в ТТГ гнейсах $-610-620^{\circ} \mathrm{C}$; для лейкосом возраста 1.88-1.89 млрд. лет в амфиболитах и диафторированных эклогитах $-610-640^{\circ} \mathrm{C}$. Для лейкосомы участка Гридино с возрастом 1.94 млрд. лет полученная температура кристаллизации составляет $760-770^{\circ} \mathrm{C}$.

Таблица 2. Возраст и температура кристаллизации структурно-привязанных лейкосом.

Table 2. Age and crystallization temperature of structurally-constrained leucosomes.

\begin{tabular}{|c|c|c|c|}
\hline Проба & Порода & Возраст, млн. лет & $\begin{array}{c}\mathrm{T}^{\circ} \mathrm{C} \text { по } \\
\text { (Watson, } \\
\text { Harrison, } \\
1983 \text { ) }\end{array}$ \\
\hline \multicolumn{4}{|c|}{ Участок Куру-Ваара } \\
\hline KT-813120 & Пегматоидная лейкосома в амфиболитах & $1888 \pm 40$ & 634 \\
\hline КТ-17216 & $\begin{array}{l}\text { Лейкогранитная лейкосома в диафторированных экло- } \\
\text { гитах }\end{array}$ & $1888 \pm 8$ & 696 \\
\hline$\Gamma-71325$ & $\begin{array}{l}\text { Лейкосома, параллельная осевым поверхностям складок } \\
\text { в ТТГ гнейсах }\end{array}$ & $1933 \pm 59$ & 613 \\
\hline$\Gamma-71325-10$ & Плагиогранит (ТТГ гнейс) & $1961 \pm 46$ & 619 \\
\hline KT-17215 & Тоналитовая лейкосома в диафторированных эклогитах & $2829 \pm 11$ & 769 \\
\hline \multicolumn{4}{|c|}{ Участок Гридино, о. Избная Луда } \\
\hline 81660 & $\begin{array}{l}\text { Лейкосома, параллельная осевой поверхности складки в } \\
\text { сдвиговой зоне }\end{array}$ & $1941 \pm 17$ & 769 \\
\hline
\end{tabular}

Авторы благодарны Т.В. Каулиной за предложенную идею для написания данной работы и В.В. Балаганскому за предоставленные образцы и ценные рекомендации.

Исследования выполнены в рамках Госзадания ГИ КНЦ РАН (0226-2019-0052) при поддержке программы президиума РАН № 19 «Фундаментальные проблемы геолого-геофизического изучения литосферных процессов».

\section{Литература}

1. Володичев О.И. Беломорский комплекс Карелии (геология и петрология). Л.: Наука. 1990. 248 с.

2. Володичев О.А., Слабунов А.И., Бибикова Е.В., Конилов А.Н., Кузенко Т.И. Архейские эклогиты Беломорского подвижного пояса, Балтийский щит // Петрология. 2004. Т. 12. № 6. С. 609-631.

3. Картушинская Т.В. Гранитоиды в Беломорском эклогитсодержащем амфиболитогнейсовом комплексе (Балтийский щит): этапность образования, корреляция с деформациями, петрография и геохимия. Выпускная квалифик. работа аспиранта. Апатиты: ГИ КНЦ РАН. 2018.

4. Мельник А.Е., Скублов С.Г., Марин Ю.Б., Березин А.В., Богомолов Е.С. Новые данные о возрасте (U-Pb, $\mathrm{Sm}-\mathrm{Nd}$ ) гранатитов в салминских эклогитах, Беломорский подвижный пояс // Доклады Академии наук. 2013. T. 448. № 2. С. 197-205.

5. Минц М.В., Конилов А.Н., Докукина К.А. и др. Беломорская эклогитовая провинция: уникальные свидетельства мезо-неоархейской субдукции и коллизии // Доклады Академии наук. 2010. Т. 434. № 6. C. 776-781.

6. Ранний докембрий Балтийского щита / Отв. ред. В.А. Глебовицкий. СПб.: Наука. 2005. 711 с.

7. Скублов С.Г., Балашов Ю.А., Марин Ю.Б., Березин А.В., Мельник А.Е., Падерин И.П. U-Рb-возраст и геохимия цирконов из салминских эклогитов (месторождение Куру-Ваара, Беломорский пояс) // Доклады Академии наук. 2010 а. Т. 432. № 5. С. 668-675. 
8. Скублов С.Г., Березин А.В., Марин Ю.Б., Ризванова Н.Г., Богомолов Е.С., Сергеева Н.А., Васильева И.М., Гусева В.Ф. Комплексное изотопно-геохимическое ( $\mathrm{Sm}-\mathrm{Nd}, \mathrm{U}-\mathrm{Pb}$ ) исследование салминских эклогитов // Доклады Академии наук. 2010 б. Т. 434. № 6. С. 802-806.

9. Слабунов, А.И., Бибикова Е.В, Степанов, В.С. Володичев О.И., Балаганский В.В., Степанова А.В., Сибелев О.С. Неоархейский Беломорский подвижный пояс // Строение и динамика литосферы Восточной Европы: результаты исследований по программам ЕВРОПРОБЫ. М.: ГЕОКАРТ-ГЕОС. 2006 а. С. 127-135.

10. Слабунов А.И., Лобач-Жученко С.Б., Бибикова Е.В., Балаганский В.В., Сорьонен-Вард П., Володичев О.И., Щипанский А.А., Светов С.А., Чекулаев В.П., Арестова Н.А., Степанов В.С. Архей Балтийского щита: геология, геохронология, геодинамические обстановки // Геотектоника. 2006 б. № 6 С. 3-32.

11. Травин В.В., Козлова Н.Е. Локальные сдвиговые деформации как причина эклогитизации (на примере структур Гридинской зоны меланжа, Беломорский подвижный пояс) // Доклады Академии наук. 2005. T. 405. № 3. С. 376-380.

12. Травин В.В., Степанов В.С., Докукина К.А. Характеристика и условия образования тектонитов острова Избная Луда (район села Гридино, северо-западное Беломорье) // Геология и полезные ископаемые Карелии. 2005. Вып. 8. С. 40-49.

13. Щипанский А.А., Ходоревская Л.И., Конилов А.Н., Слабунов А.И. Эклогиты Беломорского пояса (Кольский полуостров): геология и петрология // Геология и геофизика. 2012 а. Т. 53. № 1. С. 3-29.

14. Щипанский А.А., Ходоревская Л.И., Слабунов А.И. Геохимия и изотопный возраст эклогитов беломорского пояса (Кольский полуостров): свидетельства о субдуцировавшей архейской океанической коре // Геология и геофизика. 2012 б. Т. 53. № 3. С. 341-364.

15. Balagansky V.V., Shchipansky A.A., Slabunov A.I., Gorbunov I.A., Mudruk S.V., Sidorov M.Yu., Azimov P.Ya., Egorova S.V., Stepanova A.V., Voloshin A.V. Archaean Kuru-Vaara eclogites in the northern Belomorian Province, Fennoscandian Shield: Crustal architecture, timing, and tectonic implications // International Geology Review. 2015. V. 57, N. 11-12. P. 1541-1563.

16. Mints M.M., Belousova E.A., Konilov A.N., Natapov L.M., Shchipansky A.A., Griffin W.L., O’Reilly S.Y., Dokukina K.A., Kaulina T.V. Mesoarchean Subduction Processes: 2.87 Ga eclogites from the Kola Peninsula, Russia // Geology. 2010. V. 38. N. 8. P. 739-781.

17. Watson E.B., Harrison T.M. Zircon saturation revisited: temperature and composition effects in a variety of crustal magma types // Earth and Planetary Science Letters. 1983. V. 64. P. 295-304. 